\title{
THE METHODOLOGICAL IMPORTANCE OF THE NOTION OF DIVINE REVELATION IN A HISTORICAL PERSPECTIVE
}

\begin{abstract}
I offer an overview of the relevance of the notion of divine revelation to the methodology of the sciences. The notion of revelation is to be considered in the framework of a well-formed philosophical theory. In such a theory, the theological notion of revelation is important as well, because as a historically evolving notion it has contributed, in its own fashion, to the formation of other sciences. The method the notion of revelation entails is instructive for the methodological presuppositions of the sciences. Most importantly, the dynamism given in the notion of revelation to produce genuine newness - ad intra as well as ad extra - appears to be the decisive methodological factor defining scientific methodology. I also reflect on the importance of various forms of knowledge apodicticity, certainty and probability - as they appear in the notion of revelation and define scientific forms of knowledge in a historical as well as logical fashion. Finally, I show the place of the methodological discussion in an overall view of revelation as a well-formed philosophical theory.
\end{abstract}

Keywords: Divine revelation, theology, philosophy, methodology, science, history, newness.

1. Introduction: The Centrality of the Notion of Divine Revelation

Divine revelation is one of the central terms in the epoch in which we live. This epoch is the epoch of Christianity with all its intrinsic and extrinsic features, together with its rise and flourishing, decline and even dissolution. Revelation, nevertheless, is the most fundamental notion in this tradition, a notion that comes before other notions in the logical order, such as being, time, history, society, person, wisdom, morality, philosophy, or science. The reason of the primacy of the notion of revelation is simple: in principle, it is revelation that defines itself and its outcomes, nature and human beings included. On a histori- cal scale, it is revelation in its specific Christian form that has defined the development of Christianity including its crises and fragmentations. On a theological scale, the revelation in question is revelation in a unique sense which is characteristically different from other notions of revelation in the history of religions, while these other notions are in many ways related to the notion of revelation in Christianity.

These three kinds of relevance - logical, historical, and theological - should be investigated separately. Here I confine myself to the logical investigation of the primacy of revelation taken in itself. Other aspects of this problem, such as the historical importance and the relationship to other religious forms 
must be limited to the context of the main topic of my present text, the methodological importance of revelation. Indeed, the Christian form of revelation calls for a historical analysis of the relationship between other forms of revelation and thus also for an encompassing notion of divine revelation in which such relations can be scrutinized. However, it is precisely the Christian notion of revelation which is the basis of such a general notion, so here I can confine myself to the latter taken in the perspective of methodology.

On the logical level, revelation is conceived as the ultimate source of all reality and knowledge. The recognition of the primacy of revelation itself belongs to the effects of revelation. Inasmuch as revelation is defined as the source of reality, revelation is not reality in this sense, but is more original than reality; revelation embodies the source of reality, its realness. That is to say, revelation as the revelation of the real is taken in its utmost significance. Reality in its various forms, such as empirical, mental, external or internal reality, the reality of time and history, or even the eschatological dimension of reality, is contained in, and expressed through, revelation. Inasmuch as our knowledge is rooted in the knowledge of revelation, our knowledge is revelation-bound or, to be more precise, its main function is the reflection of revelation on various levels.

Such an approach to revelation undoes any substantive metaphysics and ontology which presuppose some kind of original stuff, matter or spirit, or perhaps a set of ideas or ideals which has been progressively developed in the course of history. In this sense, the theory of revelation - which I have re- peatedly termed 'apocalyptics' - is the reflection of the knowledge of revelation on the realness of revelation, a realness that is presupposed, reflected, and disclosed in the theory itself. $^{1}$

One may rightly ask as to how the present notion of revelation is related to the received view of divine revelation interpreted in the framework of religion. My approach in this context is philosophical which takes as its basis the historical notion of revelation as is given in Christianity and it considers all other forms of revelation as logical and, partially, historical ramifications of that central notion. Let us recall that in Christianity the realness of reality is disclosed in the revelation of incarnation. As a result, we become aware of the Trinity as the basic structure of the divine both in itself and as the source of reality. As a secondary result, we become aware of the fact that our becoming aware of revelation as the disclosure of the realness of the real is itself the working of revelation. ${ }^{2}$

Traditionally, revelation is classified into 'natural revelation' - the revelation given in creation - and 'supernatural revelation' - revelation given in the incarnation of the second person of the Trinity and its effects on the course of history. Part and parcel of natural

1 Cf. Mezei, Balázs M.: Radical Revelation: A Philosophical Approach. New York: Bloomsbury (forthcoming in 2017).

2 The Trinitarian notion of Revelation is considered here is having produced all other forms of revelation on the logical level, but partially also historically. For instance, the notion of revelation in Islam is considered as a development of the Christian notion, a development overemphasizing just one aspect of the original notion, the aspect of transcendence. 
revelation is 'natural reason', but this reason is directly enlightened by supernatural revelation with respect to the subject matter of the latter. However, reason, either natural or illuminated, needs to be aware of its own limits concerning the intrinsic features of supernatural revelation. 'Mystery' is still a term we can apply here to describe the relation of supernatural revelation to our mind. But even with this limitation, reason is capable of recognizing the centrality of revelation in its own workings as well as in what is called nature outside reason. Both in the world and the mind, revelation has a centrally important position as source and structure. ${ }^{3}$

As to the problem of methodology of a philosophical research of revelation, let me refer to a third traditional notion of revelation: 'private revelation'. 4 Traditionally, a revela-

3 See also my other work: Mezei, Balázs M.: Religion and Revelation after Auschwitz. New York: Bloomsbury, 2013.

4 In his work De revelatione Reginald GarrigouLagrange explains that the notion of revelation can be classified according to the Scholastic doctrine of causes. That is, the notion of revelation is to be investigated in accordance with its form, its agent, its material cause and its final cause. Formally, revelation can be supernatural in terms of its substance or in terms of its mode. Still as supernatural, revelation can be defined in accordance with the fashion in which it is revealed or in accordance with the psychological state of the receiver of revelation. On the side of the agent, revelation can be active or passive; as to its material cause, it can be immediate or mediate. Finally, as to its final cause, revelation can be private or public. Cf. Garrigou-Lagrange, Réginald: De revelatione per Ecclesiam Catholicam proposita. Romae: tion is considered private if and only if it remains in the framework of 'public' or 'general' revelation yet a certain interpretation of personal importance is attached to the general doctrines of revelation. Moreover, private revelation is revealed to the receiver of revelation in special ways the essence of which is the emergence of the unique awareness of the reception of revelation. It is not the possible contents of private revelation that concerns me here but rather the fact that revelation as such possesses an ultimately personal relation to human beings in their attempts to conceive revelation. Indeed, revelation in its entirety is public both as given in nature and in history. But any aspect of revelation can be conceived and understood exclusively on the grounds of a private communication, that is, in the framework of my own understanding of revelation. This understanding is not something foreign to revelation but its most important dimension, its being understood, conceived, or received.

Thus the private aspect of revelation emerges as the actual method in which revelation as such is conceived. In this way, the function of revelation as received revelation is expressed and this function is the basis of the philosophical methodology applied here. Revelation is revealed so that its overall structures may be conceived, understood and properly interpreted through its function of a personal, subjective, or 'private' communication.

Libreria Editrice Religiosa, 1951, vol. 1, pp. 153-54. 
2. Revelation and the Sciences: A Historical Outline

We tend to interpret the notion of revelation in a framework which is denoted theological and is strictly separated from other fields of human knowledge. However, revelation both in its original form and its effects on the broader human culture is not a notion rigidly separated from the other fields of human awareness. This point can be underpinned in three different ways: on Biblical grounds, on the grounds of the history of theology, and finally on the grounds of a philosophical theory of revelation.

Revelation is given especially as the collection of writings in the form of the New Testament. The New Testament is nevertheless attached to the Old Testament just as theology is attached to the various fields of human culture. The Old Testament is traditionally considered as the preparation of the New Testament,'praeparatio evangelica', a way to Christ. This way, nevertheless, is two-directional: on the one hand, the form and contents of the New Testament could be approached from the Old Testament, and vice versa, the Old Testament could be better understood on the basis of the New Testament. Obviously, this bi-directional understanding is easily applicable on the fields of revelation and the sciences. Revelation has a formal methodological importance; the sciences, on the other hand, possess the material factor shaped by the overall form of revelation.

Indeed, the New Testament is full with references to various aspects of general human culture, aspects that are better understood in the context of revelation. Jesus teaches and what he teaches is relevant to the sciences, such as the imminent coming of the end of the world, the plurality of 'heavens', the manipulability of natural forces, such as the see and the wind, the right way to sow in agriculture, or even the possibility of crossing the limits of human life. In the letters we find further claims concerning the workings of nature, society, morality, and history. There is a trajectory in this respect in the New Testament writings: from the historical and moral teachings formed by revelation we slowly approach cosmological teachings emphasizing the structures of the universe with respect to 'the end of all times'. This trajectory culminates in the highly metaphorical Book of Revelation which aspires to give a synthetic view of cosmological, theological and moral teachings in the form of an ultimate revelation. ${ }^{5}$

As to the history of theology, it is fairly obvious that leading Church writers, such as Clement of Alexandria, Augustine, or St. Thomas Aquinas among others considered theology not as a field strictly isolated from the other fields of human knowledge but rather as a field illuminating, exacting, ordering and enriching the latter. For instance, Clement of Alexandria considered the various sciences of the Greek mind as 'fragments of the Eternal Truth' and described theological knowledge as the general framework in which such

5 See for instance James 3:7 on the taming of all animals; also 2Pet 3:8-13 where we find the doctrine of water and fire in the construction and destruction of the universe; 1 Cor 15 on the nature of bodies (earthy and heavenly), with a special emphasis on the various brightness of stars. And 1 Pet 4:7: 'But the end of all things is at hand; therefore be serious and watchful in your prayers.' 
fragments are properly conceived. ${ }^{6}$ It is a well-known fact that the scientific nature of theology is defined by Thomas Aquinas as an accomplishment of the rest of the sciences. In a similar fashion, modern theological perspectives, such as those of Teilhard de Chardin, Jacques Maritain or Hans Urs von Balthasar, consider theology as an encompassing approach not in detriment to but rather as accomplishing of the rest of the sciences.

Theology is often seen as the proper field of dealing with the problem of revelation. This is true to some extent inasmuch as theology axiomatically presupposes the notion of revelation and considers the implications presuppositions, consequences, and corollaries - of this axiom. However, by possessing revelation as its axiom, theology properly speaking is unable to consider revelation in itself, because for such a consideration we need a critical view of the axiom. This view is provided by a specific theory of revelation, a philosophy of revelation. The question what revelation is and how it is relevant to the rest of human culture, including the sciences, is then a question raised by such a theory. This philosophical theory shows that the notion of revelation, that is, the notion of an ultimate source of all knowledge and reality, has shaped the human mind in such a way that the notion of universal science could emerge. This science is not just a sum of various sets of information, theoretical or practical, but rather a truly universal science with an absolutely reliable and authoritative source and

${ }^{6}$ Clement of Alexandria: Stromata. In: Fathers of the Second Century: Hermas, Tatian, Athenagoras, Theophilus, and Clement of Alexandria, C. Cleveland (ed.). New York: Charles Scribner's Sons, p. 313. structure. Moreover, this science possesses a historical character according to which it can be developed, detailed, made even more perfect along the line of a finite historical trajectory. Revelation as fully given yet as also to be developed are the two poles in which all human investigations necessarily situate themselves. For instance, in contemporary cosmology, the reality of the universe is presupposed (even if this reality is likened sometimes to a computer simulation). And it is equally presupposed that the process of knowledge is such that it can arrive at a satisfactory understanding of the fact of the universe in the framework of a finite sequence of discoveries and their conclusions. ${ }^{7}$

In more concrete terms, let me highlight the most important features of the dependence of the sciences on the contents of the notion of revelation.

a) Creation. As among others Stanley Jaki pointed out, the rise of the modern natural sciences would not have been possible without the notion of a created universe which can be accordingly known - at least in principle - in its forms and contents. However, it belongs to the core of Christian revelation to emphasize not only the difference between

7 See the recent Isaac Asimov debate in the American Museum of Natural History on the chances that our universe is a simulation: https://www.youtube.com/watch? $\mathrm{v}=$ wgSZA3N $\underline{\mathrm{PpBs}}$ See also the summary of the debate here: http://www.space.com/32543-universe-asimulation-asimov-debate.html; and see especially Nick Bostrom's Are You Living in a Computer Simulation? at http://www.simulationargument.com/simulation.html (accessed 8/11/2016). 
the creator and the creature but also the latter's rational nature. The act of creation has been deemed to be a rational act of the creator with the rational result of the created order.

b) The essence of rationality with respect to the created order is the doctrine of causality. Human or natural reason is capable of assessing causes and effects. The reasoning faculty was most often considered, accordingly, as the arithmetical faculty capable of formalizing logical and real relationships. Logic and mathematics are the most important fields in which the notion of natural necessity (as opposed to theological necessity) could be observed, followed, and modelled in symbolic forms (such as in letter or numbers).

c) The emergence of the notion of human personhood is intrinsically bound up with the notion of divine personhood developed throughout the Trinitarian debates of the first millennium of the Christian doctrines. The translation of huposthasis into persona and the definition of the human nature of Christ in the framework of his divine personhood determined the discussions on the essence of a human being in the First Scholasticism. However only when Thomas Aquinas decided to attribute the faculty of intellect to human individuals - as a reaction to Averroism - did it become possible that an integral notion of human personhood evolved. This notion corroborated the unique nature of a human person and led, in its course, to the emergence of the modern notions of the special and intrinsic dignity of human persons.

d) Even in political science, the peculiarly double character of Western Christianity, with the doctrine of the Two Swords in its center, decisively shaped the nature of the worldly power. First, it defined worldly pow- er as subservient to spiritual power. Just in this relationship, as a consequence of its definite position, kingship was able to develop a peculiar form of independence, a form which was building up its structures for many centuries. Thus, the notion of the political government developed, in many important phases, through the influence of the spiritual realm and led to the emergence and even domination of non-spiritual notions of politics in modernity. This is the basis of the famous sentence of Carl Schmitt, according to which "all significant concepts of the modern theory of the state are secularized theological concepts". 8

e) In these developments, the peculiar understanding of history as an eschatological process is to be emphasized. The notion of the ultimate termination of the created order shaped and structured the understanding of history as a complex, dynamic, and meaningful process throughout the centuries. Thus not only the notion of history was formed - leading to eschatological ideologies of the twentieth century - but also the eschatological horizon of human existence became emphasized in various ways as essentially constitutive of being a human person.

The notion of creation as the production of a functional complexity on the basis of natural laws and other technical rules of operation is clearly the backdrop of the production of machines in modernity. True, machine production was developed to some extent even in Hellenism as is shown by the compli-

8 Schmitt, Carl: Political Theology. Four Chapters on the Concept of Sovereignty. Edited and translated by George Schwab. With a Foreword by Tracy B. Strong. Chicago: Chicago University Press, 1985, p. 36. 
cated planetarium of the so-called Antikythera Mechanism. However, the mass production of machines began only with the making of mechanical clocks, for many centuries the most advanced examples of mechanical machines. While such machines were produced on a certain level even in Antiquity, the mass production of clocks and similar machineries were clearly related to the ever more elaborated theological notion of creation as the creation of a meaningful, rule following and welldesigned complexity. The notion of creation, the theological sophistication of the doctrine of causality, and the ever more refined technologies in shaping iron, steel and wood made it possible to build such machines from the $10^{\text {th }}$ century on.

In its historical role, revelation may be compared to the source of simulation emerging in related arguments as to the nature of reality in which we live. If, as Bostrom argues in his paper I referred to, the probability that we live in a simulated universe is closer to one than to zero, then the source of this simulation is a conscious activity expressed in mathematical processes. Such an activity, however, is very close to what the original notion of divine revelation suggests, a notion nevertheless much more complex than what we gain from simulation arguments today.

\section{Problems in Methodology I: What is Revealed in Revelation?}

The first and most important task to do in this context is the description of what is revealed in revelation. The question concerning this what is the pivotal methodological question, because in all methodologies the object of method defines methodology. The second question of methodology is the how an object is reached, and I shall discuss this point below. As to the what, it is the ultimate reality of revelation that is revealed. Inasmuch as revelation is the source of reality, revelation is the revelation of the realness of reality. That is to say: in revelation reality is revealed that is in no way partial, aspectual, or particular but rather absolute, overarching, and allcontaining. Yet this generality is expressed in the factuality of revelation. Revelation is fact, the ultimate and absolute fact; it is an infinite fact in the non-reduced meaning of infinity (ת).

It is in the context of the infinite fact of revelation that particular facts, again facts of revelation, take place. Most importantly it is the fact of revelation in the form of nature that appears under the horizon of the infinite fact. Nature becomes defined with respect to the infinite fact and thus their contents and correlations become the substance given in revelation. Inasmuch as revelation is always revelation directed to the receiver of revelation, the receiver of revelation gains access to the contents and the correlation given in revelation as an infinite fact and as nature. Without this correlation, both the infinite and the finite fact of revelation would be inaccessible. Insofar as they are accessible, however, they become objects of knowledge and thus a well-defined structure of objects, under the horizon of the infinite fact, appears for the receiver of revelation.

In revelation it is revelation that is revealed above all and thus it is in revelation that we gain access to the appropriate objects and their structures for our knowledge. In the revelation of revelation, a knowable universe emerges which has a definite content - under 
the horizon of the infinite fact - and also a meaningful structure of such contents open to the enquiry of the receiver of revelation. The same point may be expressed in the following way as well: the infinite fact of revelation does not only presuppose the finite facts of revelation in the form of nature, but also the fact of the receiver of revelation as a rational subject that is capable of conceiving and knowing the reality of revelation on the basis of a rational structure. In this way, the receiver of revelation may repeat the fact of revelation in their understanding and thus produce a mental model of revelation with its contents and structures. This model may be expressed in language, in symbols, in activities, or even in moral behavior of individuals and communities. Ultimately, the model may be formed in the form of a computer of various kinds (Antikythera Mechanism or Tianhe-2). Revelation as a fact appears as the source of all factual and possible contents of various kinds of modelling.

Moreover, revelation becomes particular not merely in the natural sense but in a more concrete historical and cultural sense as well. Think of the fact of incarnation at a certain point of time, at a certain location, in the form of a concrete human being using a certain language and living in definite a historical context ('under Pontius Pilate') as the example of the particular fact of revelation. This particular fact is like a window through which we gain sight of the horizon of the infinite fact. The two levels of factuality are related to one another and are then conceived in the terms of each other: the infinite fact in the terms of the particular fact and vice versa. Thus, in the factual nature of revelation not only absolute and particular factuality are ex- pressed but also their complex relations in a historically concrete setting.

Scientific methodologies presuppose the rational universe under the horizon of the infinite fact. In some theories, this infinite fact is conceived as the original fact of the birth of the universe ('Big Bang') or perhaps a string of original explosions leading to sequential births of universes. In such theories, however, the problem of the capacity of discovering and assessing such an original fact remains obscure. How does it happen that such an original fact is a fact also for me? The naiveté of scientific objectivity is too obvious: what is 'out there' counts as the totality of the real and the role of the mind is neglected or not even identified as a problem. Yet the fact of the origin is by definition is a fact related to the fact of the mind discovering this origin, thus the two facts should be described in a unified theory which cosmological theories do not offer. The theory of revelation, however, described the original fact as entailing the receiver of revelation and offers a unified description of the two facts in the form of their correlation.

\section{Problems in Methodology II: How is Revelation Revealed?}

In the traditional accounts of revelation, we distinguish general, specific, private and final revelation. General revelation is the revelation of nature in creation. Specific revelation is the revelation given in the history of salvation. Private revelation is communication given to individuals with respect to their personal needs. And final revelation is the ultimate accomplishment of revelation at the end of all times. We can further elaborate these 
kinds of revelation in accordance with other modes of communication, but it seems to be more important to point out that by all these distinctions we presuppose an original and integral notion of revelation. This notion of revelation is the fundamental what to which there belongs an equally fundamental how of revelation. So what is this how of revelation?

My short answer is this: Revelation is the revelation of revelation in such a way that revelation is enriched by itself. The very occurrence of revelation is an occurrence that embodies self-enrichment. But how can revelation as an infinite fact self-enrich itself? The answer may be given in turning around the same question: How could not revelation as an infinite fact self-enrich itself in the occurrence of revelation? Infinity is such that it is infinitely more than itself; it is infinitely more real, more rich, more complex, more detailed, more living, more substantial than itself. This sounds paradoxical, but the very notion of infinity is paradoxical for our comprehension. Let it suffice to say that the fundamental how of revelation is its infinite self-enrichment in such a way that in all instances of revelation not only the particular contents express this self-enrichment but also the infinite horizon itself is an infinitely self-enriching horizon.

In the Biblical language we may express this notion of self-enrichment as 'making all things anew': 'Behold, I make all things new!'. ${ }^{9}$ In the original text it is clearly said that the act of making all things new is the essence of revelation - not only the essence of the Book of Revelation but also and more importantly of divine revelation itself - taken both ad intra and ad extra. And the expres-

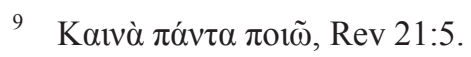

sion 'all things' does not only mean 'the heavenly Jerusalem' but indeed all things conceivable and unconceivable. Revelation, thus, is not only infinite self-enrichment but more importantly infinite self-renewal; and this infinite self-renewal is the fundamental how of revelation as revelation.

All other notions of revelation - in nature, human beings, and history - are particular exemplifications of the fundamental newness of revelation. They express this newness in particular ways; yet these ways are not unrelated to one another. Their structure is such that it is in nature that history becomes possible and it is in history that human beings receive revelation. On the other hand, all these moments are arranged along the lines of selfenriching newness, or - to use the expression of Miklos Veto - renewing newness (nouveauté novatrice). ${ }^{10}$ In this way, we may say that nature and history are just two aspects of the realization of revelation in human beings; and it is in human beings that not only the fundamental how but also the what of revelation is realized in a communicative fashion. By 'communicative fashion' I mean the notion of the 'communicatio idiomatum' or $\dot{\eta}$

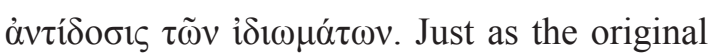
doctrine of 'antidosis' allowed the mutual acknowledgement of properties for both the divine and the human natures of Christ, human beings as receivers of revelation realize in themselves both the how and the what of revelation in the way these factors determine the reality of revelation itself. In more concrete terms: the fundamental what and how of revelation can be recognized in the receiver of

10 Vetö, Miklos, L'élargissement de la métaphysique. Paris: Hermann, 2012, p. 43. 
revelation as entailed in the reality of revelation.

Let me try to translate the above points into a more concrete example of the methodological problem. According to the fundamental discovery of the special theory of relativity, the position and movement of the observer influences the simultaneity of occurrences, the movements of clocks, mass, and length. Just as the Copernican discovery of the central position of the Earth, the special theory of relativity must take into account the position and movement of the observer so that it can properly describe the movements of objects outside the observers. In a somewhat similar fashion, quantum theory realized that the presence of an observer 'changes' the behavior of light particles travelling through a slot. In both cases, the fact, position and movement of the observer becomes decisive. Not that reality could be a subjective illusion but rather that reality is to be conceived so that the fact (and movement and position) of the observer is included into the notion of reality. What was conceived as reality in classical physics has to be enlarged to include the observer in concrete ways.

However, the theory of revelation as based on the traditional notion of revelation has always been clear about the correlational nature of revelation as being expressed in various ways but also as being addressed to the receiver of revelation. The receiver of revelation, the 'observer' as it were, is part and parcel of revelation, because revelation is such that it is to be received. It is in the structures of the receiver of revelation that the reality of revelation may be conceived; and it is the realness of revelation, as received by the receiver, that the realness of revelation may be understood. This feature of revelation can be properly called the correlational nature of revelation.

It is an implication of the physical theories mentioned that the presence of the observer not only influences the observed state of affairs but even realizes a new state of affairs. Yet it has always been the very essence of revelation that its workings have been conceived in terms of renewing newness, nouveauté novatrice. Scientific inquiry can never be conceived of in terms of merely establishing 'what is out there'. Rather, scientific inquiry needs to understand itself as contributing to reality not only theoretically but also in terms of its contents. I do not say that in science we find what we want to find, but I say that our search contributes to reality in important ways and this contribution must be taken into account in our assessment of achievements. We must begin with the fact that reality is self-enrichment and our search for knowledge - and also our production of models and machines - is a particular aspect of the self-enriching processes of reality. As often seems, such processes may be turned into self-destructive ones, and human beings has a clear responsibility here. ${ }^{11}$

11 The dimension of newness is what appears to be the most difficult obstacle to a theory of reality as a mere simulation: for in simulation no newness could be discovered, thus, to begin with, the fact of the simulation itself. 
5. Problems in Methodology III: Apodicticity, Certainty, and Probability

One of the clear mistakes of Peter Sloterdijk's theory of 'the apocalypse of the Real',12 is that he does not seem to recognize the importance of the principle of nouveauté novatrice. Sloterdijk considers the history of modernity as the history of such an 'apocalypse' and construes this process in terms of a certain emergentism. The new understanding of reality emerges out of the confusion of misleading pseudo-theories, mainly religious in nature, and the spherical emergence of a nonfossil-bound source of energy, the light of the sun, will clear our mind of the last remnants of old theories. However, old theories, especially the theory of revelation in a theological form already contained some of the most important factors shaping our scientific history and even showing us a way beyond limited interpretations of reality.

Let me show you briefly how modern science based its epistemological dogmas on certain aspects of the notion of revelation, how it isolated these aspects from one another, and finally how these aspects may be combined again on the basis of a better understood theory of revelation. Revelation appears in its Christian form as an objectively certain, even apodictically certain understanding the necessity of which outshines the necessity of philosophy, logic, or everyday experience. One of the well-known sayings of Jesus mentions natural phenomena as predicting certain occurrences; however, the level of certainty

12 Cf. Sloterdijk, Peter: Was geschah im 20. Jahrhundert? Berlin: Suhrkamp, 2016, pp. 106115. concerning divine revelation ('the signs of the times') are much higher:

'When it is evening you say, "It will be fair weather, for the sky is red"; and in the morning, "It will be foul weather today, for the sky is red and threatening." Hypocrites! You know how to discern the face of the sky, but you cannot discern the signs of the times' (Mat 16, 2-3).

The schema we find here is this: natural certainty is surpassed by revelational certainty. We may add: the certainty of revelation was deemed to surpass even philosophical, logical certainties as well, because revelation was seen as possessing the highest apodicticity possible. This apodicticity concerned the saving power of God vis-à-vis sinful human beings, that is it concerned the reality of salvation. Certainty was the personal experience of this salvific apodicticity expressed in faith, such as in Hebrew 11:1: 'Now faith is the substance of things hoped for, the evidence of things not seen.' Probability - that is the aspectual ambivalence of an assertion was delegated to the introductory realm of revelation. Probability is mentioned a number of times in the New Testament as "possibility', such as 'The things which are impossible with men are possible with God' (dunatos, Luke 18, 27).

Thus, revelational apodicticity, certainty and probability are organically connected to one another. In the perspective of a theory of revelation we may say that these dimensions of knowledge express various aspects of the same whole in which revelation as revelation is realized. This whole may be described in 
terms of truth and reality expressed by the Hebrew word 'amen' so often used by Jesus in the gospels.

In the history of the sciences, the organic relationship between apodicticity, certainty and probability disintegrates. Apodicticity in its mathematical and logical form gets rid of the two other dimensions, especially of the dimension of certainty; and probability evolves into a calculus which has gained an increasing significance in contemporary science. What the theory of revelation may teach us in this respect is twofold: on the one hand, an organic connection of these modes of knowledge is not only possible but even advisable. Thus we need to work out a new form of apodicticity which integrates the aspects of logical apodicticity, certainty, and probability. In this work, the principles of faith, hope and love are instructive. These principles describe modes of the reception of revelation in three important aspects. All have been influential in the history of the sciences, because faith became understood not merely as faith in God but also as faith in the rational order of everything; hope was understood not merely as the connection to the ultimate fulfilment of revelation but also as the hope concerning genuine understanding of ourselves and our world in which we live; and finally, love was not only understood as the love of God and our neighbors, but also as the love of knowledge, wisdom, and humanity as such.
In my understanding, these three aspects must be seen in their entirety and combined into the organic whole of the reality of revelation. We need to receive revelation and have faith in it, hope for it, and love it; but we also need to be uniquely certain of the reality of revelation which leads our world out of its present confusions and to reach a better order of things in the form of a universal renewal. This renewal makes our methodology instructive to an encompassing scientific methodology: because the aim of human knowledge is not only to understand what is 'out there', not only to produce limited models of natural goings-on in the form of machines, but rather to aim at the overall renewal of reality in which all the fragments of our knowledge and reality may be organized into a meaningful whole. The notion of revelation, as is substantiated by the theory of revelation, teaches us to follow this way.

\section{Conclusion: Methodological Apocalyptics}

What I outlined above belongs to the field I mentioned above under the title of apocalyptics. Apocalyptics is the overall form of the study of revelation. Beyond its fundamental introduction, apocalyptics has three important fields: 1. Theoretical Apocalyptics; 2. Historical Apocalyptics; 3. Methodological Apocalyptics 
Here is the structure of these fields:

\begin{tabular}{|c|c|c|c|}
\hline Structural fields & \multirow[t]{2}{*}{$\frac{\text { Methodological }}{\underline{\text { Apocalyptics }}}$} & \multirow[t]{2}{*}{$\frac{\text { Theoretical Apoca- }}{\text { lyptics }}$} & \multirow[t]{2}{*}{$\frac{\text { Historical }}{\underline{\text { lvptics }}}$} \\
\hline Content fields $\nabla$ & & & \\
\hline Contexts of Logic & $\begin{array}{l}\text { Logical problems } \\
\text { of method }\end{array}$ & $\begin{array}{c}\text { Logical problems } \\
\text { of theory }\end{array}$ & $\begin{array}{l}\text { Logical problems } \\
\text { of history }\end{array}$ \\
\hline $\begin{array}{l}\text { Contexts of } \\
\text { Philosophy }\end{array}$ & $\begin{array}{l}\text { Philosophical prob- } \\
\text { lems of } \\
\text { method }\end{array}$ & $\begin{array}{c}\text { Philosophical prob- } \\
\text { lems of } \\
\text { theory }\end{array}$ & $\begin{array}{c}\text { Philosophical prob- } \\
\text { lems of } \\
\text { history }\end{array}$ \\
\hline$\frac{\text { Contexts of }}{\text { Theology }}$ & $\begin{array}{l}\text { Theological prob- } \\
\text { lems of method }\end{array}$ & $\begin{array}{l}\text { Theological prob- } \\
\text { lems of theory }\end{array}$ & $\begin{array}{l}\text { Theological prob- } \\
\text { lems of history }\end{array}$ \\
\hline $\begin{array}{c}\text { Contexts of } \\
\text { Phenomenology }\end{array}$ & $\begin{array}{c}\text { Phenomenological } \\
\text { problems } \\
\text { of method }\end{array}$ & $\begin{array}{c}\text { Phenomenological } \\
\text { problems } \\
\text { of theory }\end{array}$ & $\begin{array}{c}\text { Phenomenological } \\
\text { problems } \\
\text { of history }\end{array}$ \\
\hline $\begin{array}{c}\text { Contexts } \frac{\text { of }}{} \\
\underline{\text { Religious }} \underline{\text { Studies }}\end{array}$ & $\begin{array}{l}\text { Problems of method } \\
\text { in religious studies }\end{array}$ & $\begin{array}{l}\text { Problems of theory } \\
\text { in religious studies }\end{array}$ & $\begin{array}{l}\text { Problems of history } \\
\text { in religious studies }\end{array}$ \\
\hline$\frac{\text { Contexts of the }}{\text { Sciences }}$ & $\begin{array}{l}\text { Problems of method } \\
\text { in investigating } \\
\text { the sciences }\end{array}$ & $\begin{array}{l}\text { Problems of theory } \\
\text { in investigating the } \\
\text { sciences }\end{array}$ & $\begin{array}{l}\text { Problems of history } \\
\text { in investigating } \\
\text { the sciences }\end{array}$ \\
\hline$\frac{\text { Contexts }}{\underline{\text { Arts }}} \frac{\text { of the }}{\underline{n^{\prime}}}$ & $\begin{array}{c}\text { Problems of method } \\
\text { in investigating } \\
\text { the arts }\end{array}$ & $\begin{array}{c}\text { Problems of theory } \\
\text { in investigating } \\
\text { the arts }\end{array}$ & $\begin{array}{c}\text { Problems of history } \\
\text { in investigating } \\
\text { the arts }\end{array}$ \\
\hline $\begin{array}{l}\text { Contexts of } \\
\text { Personhood } \\
\end{array}$ & & $c e$ & \\
\hline
\end{tabular}

All these fields are actually disciplines which consider fundamental problems of the study of revelation: its methods, its theories, and its history. As to the methodological venue, the study of revelation includes the study of the logical, theological, phenomenological, scientific, religious, and artistic problems. In other words, it considers the problems of revelation in the context of the human sciences in general. Its ultimate aim is threefold:

a) to show the organic connections among the various fields of methodologies;

b) to show the relationship between these methodologies and the fundamental method of apocalyptics; and

c) to show the relevance of such methodologies to the receiver of revelation, human personhood, in their perspective of renewing newness, nouveauté novatrice.

In my presentation, all I wished to summarize has been the special correlation between the study of revelation and scientific methodology in a general sense and in a historical perspective. While I find it very important, I did not have appropriate place to show the relevance of such a general method- 
ology to human or 'apocalyptic' personhood. However, I believe it is of paramount importance to recognize that all our considerations are worthwhile if and only if they contribute not only to a better understanding of the sciences, philosophy, or culture, but essentially to the self-renewal of human persons in their concrete historical situation.

\section{REFERENCES}

Bostrom, N. (2016). Are You Living in a Computer Simulation? at http://www.simulationargument.com/simulation.html (accessed 8/11/2016).

Clement of Alexandria: Stromata. In: Fathers of the Second Century: Hermas, Tatian, Athenagoras, Theophilus, and Clement of Alexandria, C. Cleveland (ed.). New York: Charles Scribner's Sons.
Garrigou-Lagrange, R. (1951). De revelatione per Ecclesiam Catholicam proposita. Romae: Libreria Editrice Religiosa,

Mezei, B.M. (forthcoming in 2017). Radical Revelation: A Philosophical Approach. New York: Bloomsbury.

Mezei, B.M. (2013). Religion and Revelation after Auschwitz. New York: Bloomsbury.

Schmitt, C. (1985). Political Theology. Four Chapters on the Concept of Sovereignty. Edited and translated by George Schwab. With a Foreword by Tracy B. Strong. Chicago: Chicago University Press.

Sloterdijk, P. (2016). Was geschah im 20. Jahrhundert? Berlin: Suhrkamp.

Vetö, M. (2012). L'élargissement de la métaphysique. Paris: Hermann. 